Copyright (C 2014 IEEE. Personal use of this material is permitted. Permission from IEEE must be obtained for all other uses, in any current or future media, including reprinting/republishing this material for advertising or promotional purposes, creating new collective works, for resale or redistribution to servers or lists, or reuse of any copyrighted component of this work in other works. 


\title{
Operation and Control of a Hybrid AC-DC Nanogrid for Future Community Houses
}

\author{
Ruwan P.S. Chandrasena, Farhad Shahnia, Arindam Ghosh, and Sumedha Rajakaruna \\ Electrical and Computer Engineering Department \\ Curtin University \\ Perth, Australia \\ ruwan.chandrasena@curtin.edu.au
}

\begin{abstract}
A hybrid AC-DC nanogrid (NG) can be considered as the power supply system for future community houses. In this paper, the operation and control of a NG are presented. The NG consists of an $\mathrm{AC}$ bus and a DC bus, interconnected through a tie-converter. Each bus may have several loads and micro sources. The NG should have an adequate generation capacity to supply its loads in off-grid mode as well as the capability of exchanging power with the utility grid. The tie-converter exchanges the power between two buses and regulates bus voltage in both buses in the case of off-grid operation. Several case studies are presented using PSCAD/EMTDC to verify the NG dynamics.
\end{abstract}

Index Terms-Nanogrid, Hybrid AC-DC, DER, Power Sharing.

\section{INTRODUCTION}

It is expected that in near future, the majority of householders will have distributed energy resources (DERs) connected to the utility grid. Hence, it is realistic to envision forming of a self-controlled nano-scale entity of the power system referred as 'Nano-Grid' (NG) [1] by amalgamation of resources in neighboring houses supplied by the same utility feeder. These houses, referred to as 'community houses' in this paper, can therefore share the power generated by DERs such as solar photovoltaic (PV) arrays and energy storages units (e.g. battery banks) either in off grid or grid-connected.

Nowadays, most of the domestic loads are designed to work on AC voltage; hence, proper converting systems are required to convert the DC voltage generated by some DERs to $\mathrm{AC}$ voltage. Recent researches have proposed $\mathrm{DC}$ voltage supply for certain types of residential loads [2]. In [3], an efficiency comparison is carried out for different types of residential loads supplied by AC or DC supply. It is shown that the efficiency of supplying the loads by DC voltage generated by DC generators is higher than that of supplying the loads from the converted AC supply. In [4], a new efficient DC power distribution system is proposed for future residential premises which increases total conversions efficiency from $80 \%$ to $94 \%$. A novel low voltage bipolar-type DC distribution system for residential applications was proposed and verified experimentally in [5-6]. In addition, some experiments have already been conducted on deploying smart control over AC and DC DERs within residential premises [7-8].

In this paper, a small-scale low voltage network, referred to as $\mathrm{NG}$, is considered as future power supply unit for community houses. The discussed NG integrates both AC and DC

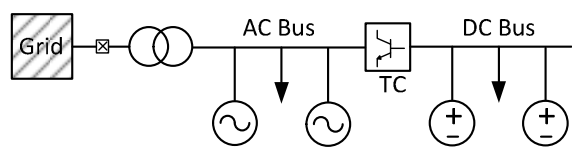

Fig. 1. Hybrid AC-DC Nanogrid structure.

types of loads and DERs connected to the respective AC or DC buses which are interconnected through a power converter. The NG may exchange power with the grid depending on the generation capacity of its DERs while being capable of operating in autonomous mode as well. The NG resembles to microgrids [9] in many ways but it is only at low-voltage level, has DERs with lower rating and spread in a much smaller geographic area. In addition, its loads are assumed to be centralized, connected to DC or AC bus.

The main contribution of this paper is proposing and validating the primary and secondary control levels for the dynamic operation of DC and AC DERs within the NG in different modes of operation. The DERs in each bus are controlled in two different modes of operation depending on the network grid-connection status. Furthermore, an interconnecting converter is utilized for voltage regulation in both $\mathrm{AC}$ and DC bus while providing the power flow exchange capability between the two buses. Several case studies are investigated for different modes of operation of the NG system using PSCAD/EMTDC. Through the simulation results, the dynamic performance of DERs in NG system is verified.

\section{HYBRID AC-DC NANOGRID STRUCTURE}

Let us consider a NG structure consisting of an $\mathrm{AC}$ bus and a DC bus, as shown in Fig. 1. A Tie-Converter (TC) is used for interconnecting the $\mathrm{AC}$ and $\mathrm{DC}$ bus together. The $\mathrm{AC}$ bus is also connected to the grid through a solid-state static switch and supplied through a three-phase transformer. Each bus has some loads and generation units connected.

In this study, the AC bus is assumed to be a three-phase $400 \mathrm{~V}$ system supplied by a $30 \mathrm{kVA}$, three-phase transformer. The DC bus is assumed to be a $350 \mathrm{~V} \mathrm{DC}$ system. Two power-electronic interfaced DERs are assumed to be connected to the AC bus and another two power-electronic interfaced DERs are assumed to be connected to the DC bus.

The introduced NG structure should be controlled such that the system can successfully operate dynamically in different modes of grid-connection and isolation while the TC is in 
conducting and non-conducting mode. Appropriate primary control levels are required for the DERs in the considered NG structure for a successful dynamic operation. This is discussed in detail in Sections III and IV. The structure and control of the inter-connecting TC between the AC and DC bus is discussed in Section V. In addition, the central controller which monitors and coordinates the performance of the DERs and the TC is discussed in Section VI.

\section{AC NANOGRID STRUCTURE AND CONTROL}

Let us consider a three-phase AC NG formed by a group of AC DERs and loads, connected to the same bus. Each DER is connected to the AC bus through a three-phase Voltage Source Converter (VSC) with an LC filter in its output (Fig. 2a). Each VSC consists of three single-phase $\mathrm{H}-$ bridges. The output of each $\mathrm{H}$-bridge is connected to a single-phase transformer, with 1: $a$ turns ratio. The transformers are connected in star in their secondary side and provide galvanic isolation and voltage boosting capability, if required. In this figure, the resistance $R_{f}$ represents the switching and transformer losses, while the inductance $L_{f}$ represents the leakage reactance of the transformer and the filter capacitor $C_{f}$ is connected to the output of the transformers to bypass the switching harmonics. The single-phase equivalent circuit of the DER converter and filter (Fig. 2b). A coupling inductance $\left(L_{T}\right)$ is installed after the AC filter capacitor to provide desired power sharing among the DERs.

The AC MG control consists of several modules, namely synchronization/islanding detection, DER converter output power control and converter switching control modules.

Depending on the state of the solid-state static switch, the NG operates in either grid-connected or off-grid mode. In this study, islanding detection is based on monitoring the switch status and the assumption of communication interface availability to transfer information to DERs [9].

\section{A. Power Output Control Module}

In AC NG, the DER converters are operated on constant PQ mode when the NG is in grid-connected and on voltage control mode based on droop, during off-grid. For this, two different converter output voltage references are required:

In grid-connected mode, the grid dictates the network voltage and frequency. Hence, the DERs are expected to generate the power at their rated capacities. In such a case, the active $(p)$ and reactive power $(q)$ at the Point of Common Coupling (PCC) of the coupling inductances $\left(L_{T}\right)$ is can be expressed as

$$
\begin{aligned}
& p=\frac{\left|V_{T}\right| \times\left|V_{c f}\right|}{\omega L_{T}} \sin \left(\delta_{c f}-\delta_{T}\right) \\
& q=\frac{\left|V_{T}\right|}{\omega L_{T}}\left(\left|V_{c f}\right| \cos \left(\delta_{c f}-\delta_{T}\right)-\left|V_{T}\right|\right)
\end{aligned}
$$

where $V_{T}$ is the voltage at converter PCC, $V_{c f}$ is the voltage across the AC filter capacitor and $V=|V| \angle \delta$ is the phasor representation of $v(t)$. The average active power $(P)$ and reactive power $(Q)$ can be derived by passing their instantaneous values through a low pass filter. Assuming the rated values

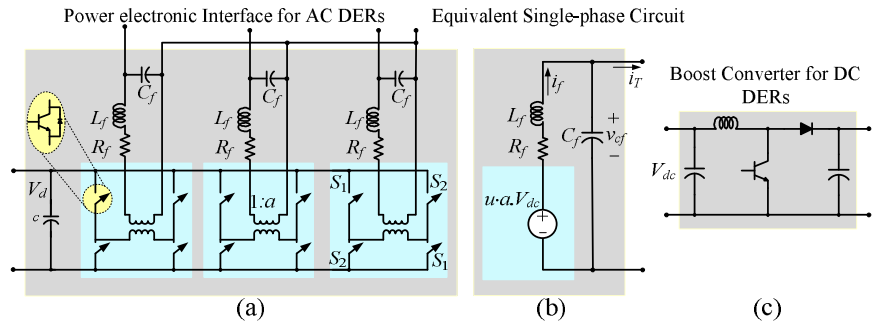

Fig. 2. (a) Power electronic interface for DERs connected to AC and DC bus.

for the active and reactive power and monitoring the PCC voltage, the desired $v_{c f}$ can be calculated using (1). This is the voltage reference in grid-connected mode in Fig. 3.

In off-grid mode, the output voltage and frequency of DER converters are varied based on droop using pre-defined droop coefficients $(m, n)$ to regulate the network voltage and frequency within acceptable limits, while sharing the loads in the network with the specified ratio. Hence, the active and reactive power delivered by the DERs are measured and used to derive the reference DER converter output voltage as [9]

$\delta_{c f}=\delta_{\text {ac, rated }}-m\left(P_{a c, \text { rated }}-P_{a c}\right)$

$\left|V_{c f}\right|=V_{a c, \text { rated }}-n\left(Q_{a c, \text { rated }}-Q_{a c}\right)$

where the suffix rated shows the rated values and the suffix ac shows the droop among DERs in the AC bus. This will be the voltage reference for the converter in off-grid mode in Fig. 3. A detailed description on the design of droop coefficients based on the ratings of the DERs and the design of coupling inductances is provided in [9].

\section{B. Converter Switching Control Module}

Converter switching control module is responsible for proper turn on/off of the IGBTs in VSC such that the desired reference voltage is generated across the AC filter capacitor in both operation modes. In this study, a closed-loop optimal linear robust controller based on state feedback control is used to generate the switching function $u$. Assuming a bipolar switching for the IGBTs, $u$ can take \pm 1 value which will subsequently turn on/off IGBTs in the converter [10].

\section{DC NANOGRID STRUCTURE AND CONTROL}

Let us consider a DC MG formed by a group of DC DERs and loads, connected to the same bus. Each DER is connected to the DC bus through a DC-DC converter. For a batterybased DER, a four-quadrature converter is required to provide bidirectional power flow between the battery and the DC bus. For other DC DERs, a simpler DC-DC converter can be deployed. In this study, a boost converter is utilized for connecting the DERs to the DC bus (Fig. 2c). The inductor and capacitor are designed to reduce current and voltage ripples.

The DC MG control consists of several modules, namely TC conduction status monitoring, DER converter output power control and converter switching control modules.

In this study, the AC NG islanding detection method is based on monitoring the status of the TC and the assumption of communication interface to transfer this information. 


\section{A. Power Output Control Module}

Depending on the status of the TC, the DERs in the DC bus will operate in two different modes:

If the TC is on (i.e. conducting), the DC DERs are controlled in constant $\mathrm{P}$ mode. In this case, the DC bus voltage will be regulated to a desired value by controlling the bidirectional power flow through the TC.

If the TC is off (i.e. non-conducting), the DC DERs are operated in voltage control mode, based on droop. In this case, the voltage of each DER converter is varied based on the droop control and pre-defined droop coefficients $\left(m^{\prime}\right)$ to regulate the DC bus voltage within acceptable limits, while sharing the loads of the DC bus. Hence, the active power $(P)$ delivered by the DERs are measured and used to derive the reference converter output voltage as [11]

$V_{d c}=V_{d c, \text { rated }}-m^{\prime}\left(P_{d c, \text { rated }}-P_{d c}\right)$

where the suffix $d c$ shows the droop among DERs in the DC bus. This will be the voltage reference for the DC DER converters in non-conducting mode of the TC, in Fig. 3. A detailed description on the design of droop coefficients based on the ratings of the DERs is provided in [9].

\section{B. Converter Switching Control Module}

The boost converter of each DC DER is controlled to provide the desired control as discussed in the previous subsection, as discussed in [12].

\section{TIE-CONVERTER STRUCTURE AND CONTROL}

The AC and DC bus in the considered NG structure are interconnected together through a TC. The TC has a threephase VSC, connected through an LC filter to AC bus, with a structure similar to those of AC DERs.

The TC is operated in voltage control mode and is responsible for correcting its Point of Common Coupling (PCC) voltage to a three-phase balanced voltage in the $\mathrm{AC}$ side as well as regulating the DC bus voltage. The TC regulates its PCC voltage to the desired value by exchanging reactive power with the AC bus. The DC bus voltage regulation is achieved by adjusting the angle of the voltage across the $\mathrm{AC}$ filter capacitor $\left(\delta_{c f, T C, r e f}\right)$ in PCC of TC as

$\delta_{c f, \text { tie-converter, } r e f}=\left(k_{P}+\frac{k_{I}}{s}\right)\left(V_{d c, \text { desired }}-\widehat{V}_{d c}\right)$

where $\hat{V}_{d c}$ is the average of the DC bus voltage, $V_{d c, d e s i r e d}=$ $350 \mathrm{~V}$ in this study, and $k_{P}$ and $k_{I}$ are Proportional-Integrator (PI) coefficients. A VSC switching algorithm, similar to the ones of AC DERs, is deployed for TC switching control.

\section{CENTRAL CONTROLLER}

The secondary level control (central controller) is responsible for regulating the voltage magnitude and frequency in the $\mathrm{AC}$ bus as well as the voltage magnitude in the $\mathrm{DC}$ bus, by adjusting the reference values for the primary controller, whenever required.

If the voltage magnitude or frequency in the $\mathrm{AC}$ bus or the voltage magnitude in the DC bus rises above or drops below

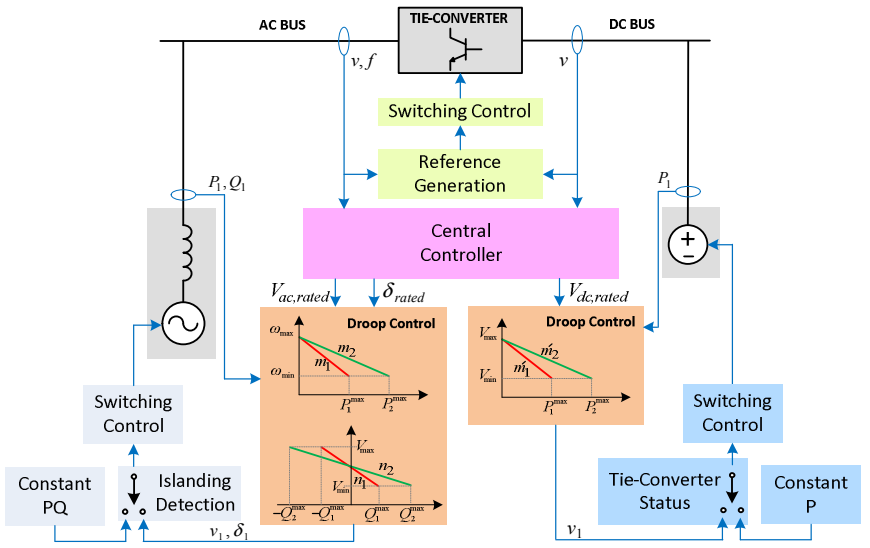

Fig. 3. Primary and secondary control levels of the considered NG system.

the acceptable pre-defined values, the central controller takes action to shift up or down the DERs droop characteristic based on new rated voltage and frequency references. The new rated voltage and frequency will be defined based on old rated values and the difference of these parameters with their desired values from

$$
\begin{aligned}
& \omega_{a c, \text { rated }}^{\text {new }}=\omega_{a c, \text { rated }}^{\text {old }}+2 \pi\left(f_{\text {desired }}-f\right) \\
& V_{a c, \text { rated }}^{\text {new }}=V_{a c, \text { rated }}^{\text {old }}+V_{a c, \text { desired }}-\left|V_{a c}\right|
\end{aligned}
$$

where $\left|V_{a c}\right|$ and $f$ are respectively the voltage magnitude and frequency in the $\mathrm{AC}$ bus while $f_{\text {desired }}=50 \mathrm{~Hz}$ and $V_{\text {ac,desired }}=$ $240 \mathrm{Vrms}$, in this study. Similarly, for the DC bus, the new rated voltage is defined as

$$
V_{d c, \text { rated }}^{\text {new }}=V_{d c, \text { rated }}^{\text {old }}+V_{d c, \text { desired }}-\widehat{V}_{d c}
$$

Note that this controller runs in a much slower time frame compared to the primary level controllers discussed in Sections III and IV.

The central controller performance for different modes of operation of NG is summarized as:

- If the NG is off-grid, the central controller will act as the secondary level control for each DER in both the AC and DC bus. In this case, the central controller will define the rated voltage magnitude and frequency for the DERs in the $\mathrm{AC}$ bus, as well as the rated voltage for the DERs in the DC bus, as shown schematically in Fig. 3.

- If the $\mathrm{AC}$ bus of NG is grid-connected while the TC is off, the central controller is only responsible for defining the rated voltage magnitude for the DERs in the DC bus as the DERs in the AC bus are operating in constant PQ mode with power exchange capability with the grid.

- If the $\mathrm{AC}$ bus of NG is grid-connected while the TC is on, the central controller is inactive and not regulating the voltage and frequency in the $\mathrm{AC}$ nor the $\mathrm{DC}$ bus.

\section{STUdy CASES AND SIMULATION RESULTS}

To investigate the performance of the hybrid AC-DC NG, with the proposed control strategies, different operation modes are studied using PSCAD/EMTDC with the technical data provided in the Appendix. 
a) AC DERs Active Power

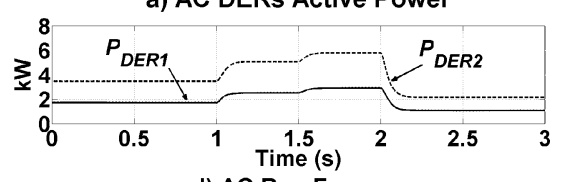

d) AC Bus Frequency

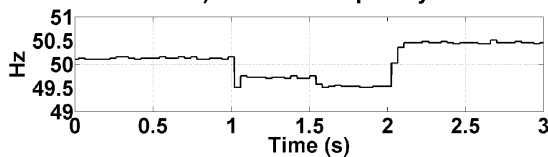

Fig. 4. Simulation results for the AC bus in Case 1.

a) DC DERs Active Power

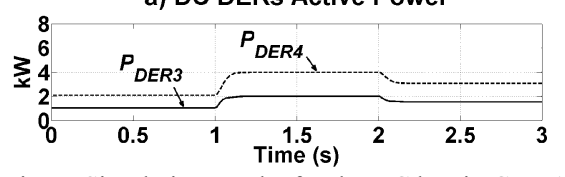

Fig. 5. Simulation results for the DC bus in Case 1

a) AC DER Active Power

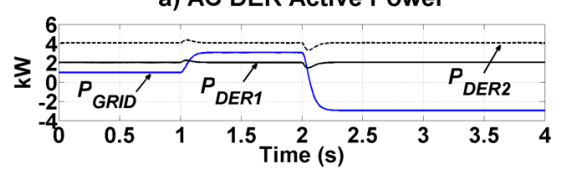

d) AC Bus Frequency

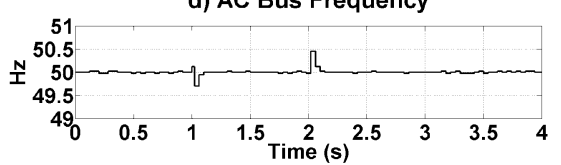

Fig. 6. Simulation results for the AC bus in Case 2 .

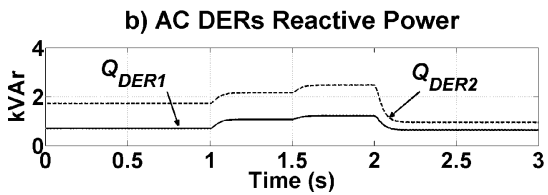

e) AC Bus Voltage RMS

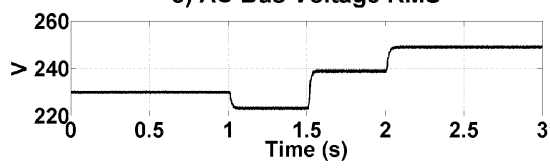

b) DC Load Power

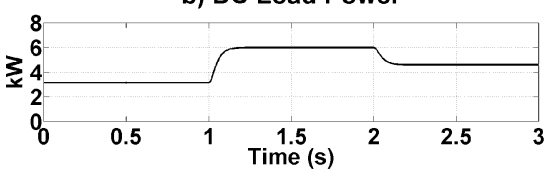

b) AC DER Reactive Power

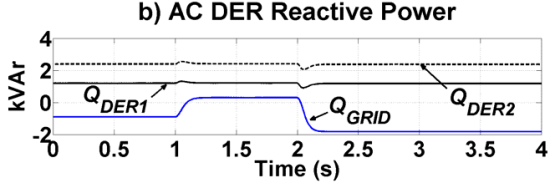

e) AC Bus Voltage RMS

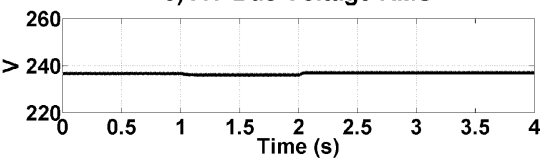

c) AC Load Active Power

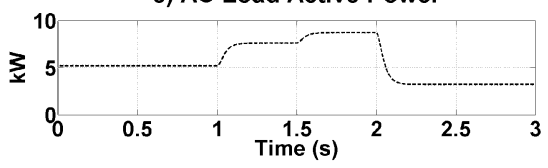

f) AC Bus Rated Voltage

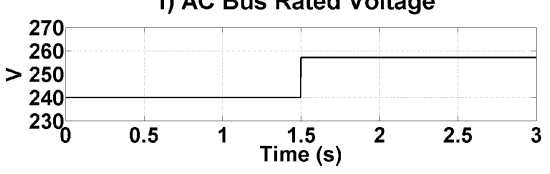

c) DC Bus Voltage

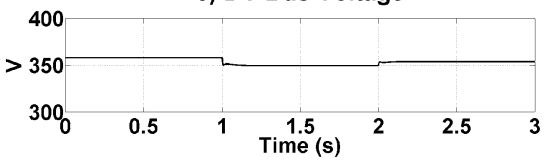

c) Load Active Power

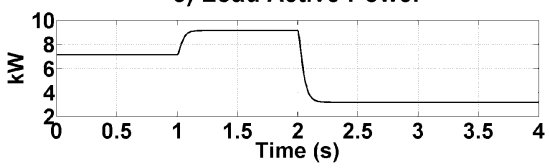

\section{A. Case 1}

The TC is assumed to be in non-conducting mode; hence, the $\mathrm{AC}$ and $\mathrm{DC}$ bus are isolated while the $\mathrm{AC}$ bus is assumed to be islanded from the grid. Under such conditions, the DERs in each bus share the load of the relevant bus and the central controller regulates the $\mathrm{AC}$ and $\mathrm{DC}$ bus voltage in \pm $10 \%$ range and the frequency of $\mathrm{AC}$ bus in $\pm 0.5 \mathrm{~Hz}$ range.

Let us consider the network is in steady-state condition initially with a total load demand of approximately $6 \mathrm{~kW}$ in the AC bus. At $t=1 \mathrm{~s}$, this load is increased by $3 \mathrm{~kW}$ (i.e. $50 \%$ ) and at $t=2 \mathrm{~s}$, the network load is decreased by $6 \mathrm{~kW}$ (i.e. $66 \%$ ). The output active and reactive power ratio among DER-1 and 2, connected to the AC bus is maintained as assigned (i.e. 1:2) for all load changes (Fig. 4a-b) while the load active power variation (Fig. 4c). The frequency variations in the $\mathrm{AC}$ bus are within the acceptable limits of \pm 0.5 $\mathrm{Hz}$, as shown in Fig 4(d). The AC Bus voltage RMS drops below the minimum acceptable limit of $-10 \%$ after the load increase at $t=1 \mathrm{~s}($ Fig. $4 \mathrm{e})$. Therefore, at $t=1.5 \mathrm{~s}$, the central controller has applied an adjustment in the droop curve characteristic of the DERs by increasing the rated voltage from 240 to $258 \mathrm{~V}$ (Fig. 4f); hence, the AC bus voltage is restored to approximately $240 \mathrm{~V}$. After load reduction at $t=2 \mathrm{~s}$, the $\mathrm{AC}$ bus voltage rises but does not exceed the maximum limit; hence central controller does not take any further action.

Similarly, the DERs in the DC bus share the loads in DC bus. Let us assume the network is in steady-state condition initially with a total load demand of $3 \mathrm{~kW}$ in the DC bus. At $t=1 \mathrm{~s}$, this load is increased by another $3 \mathrm{~kW}$ (i.e. $100 \%$ ) and at $t=2 \mathrm{~s}$, the network load is decreased by $1 \mathrm{~kW}$ (i.e. $17 \%$ ). The output active power ratio among DER-3 and 4, connected to the DC bus is maintained successfully as assigned (i.e. 1:2) for all load changes (Fig. 5a) for the load changes (Fig. 5b). The DC Bus voltage is kept within the acceptable limit, (Fig. 5c); hence no action is taken by the central controller.

\section{B. Case 2}

The TC is assumed to be in non-conducting mode; hence the $\mathrm{AC}$ and $\mathrm{DC}$ bus are isolated while the $\mathrm{AC}$ bus is assumed to be connected to the grid. Under such conditions, the DERs in the $\mathrm{AC}$ bus operate in constant PQ mode, in their rated conditions, while the DERs in the DC bus operate in voltage control, based on droop and the central controller regulates only the DC bus voltage, in a slower time frame.

Let us consider the network is initially in steady-state condition with a load demand of approximately $7 \mathrm{~kW}$ in the $\mathrm{AC}$ bus. At $t=1 \mathrm{~s}$, this load is increased by $2 \mathrm{~kW}$ (i.e. $29 \%$ ) and at $t=2 \mathrm{~s}$, decreased by $6 \mathrm{~kW}$ (i.e. $66 \%$ ). The output active and reactive power of DER-1 and 2, connected to the AC bus is shown in Fig. $6 \mathrm{a}-\mathrm{b}$ while the load active power variations are shown in Fig. 6c. The frequency of the AC bus is $50 \mathrm{~Hz}$, as shown in Fig 6d. The AC Bus voltage RMS is shown in Fig. 6e. The performance of DERs in the DC bus will be similar to the results in Fig. 5. 
a) AC DERs Active Power

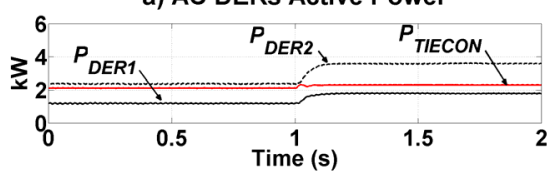

d) AC Bus Frequency

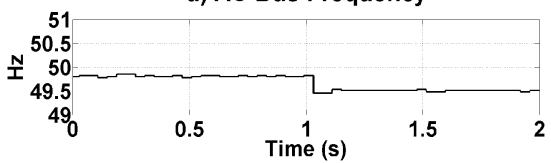

b) DC DERs Power

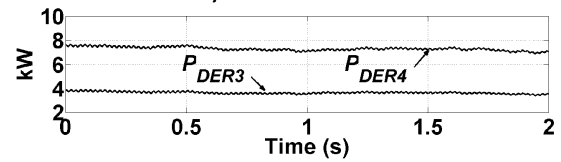

e) AC Bus Voltage RMS

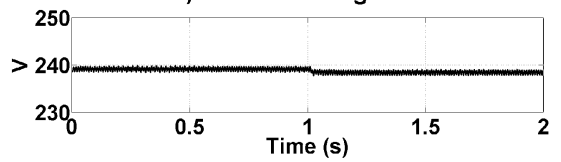

c) Load Active Power

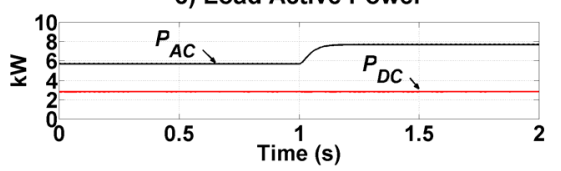

f) DC Bus Voltage

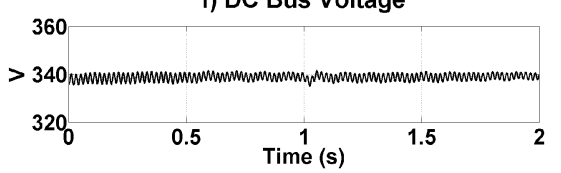

Fig. 7. Simulation results for the AC and DC bus in Case 3.

a) AC DERs Active Power

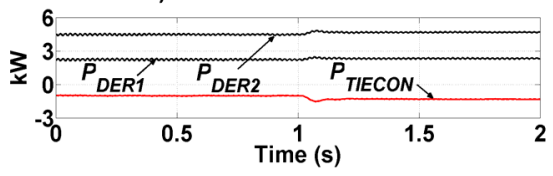

b) DC DERs Active Power

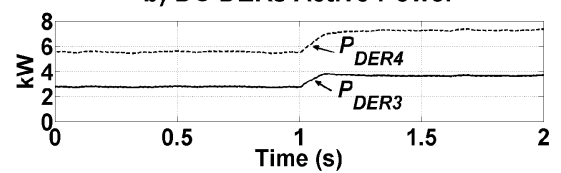

c) Load Active Power
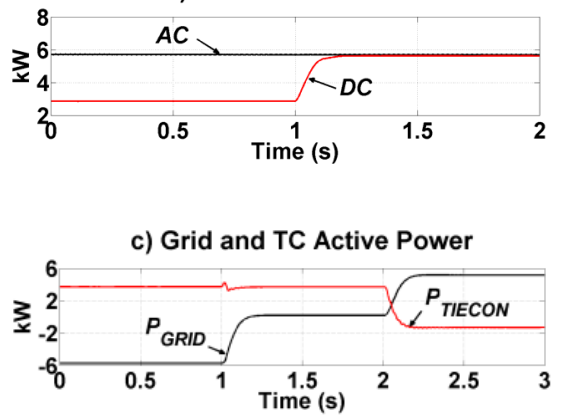

b) DC DER Power

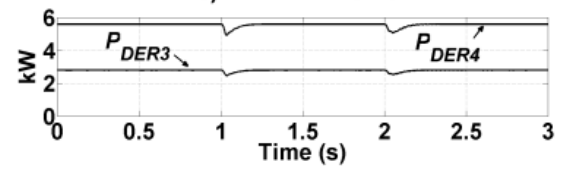

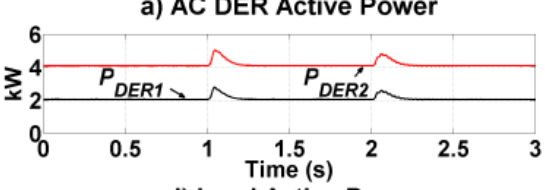

d) Load Active Power

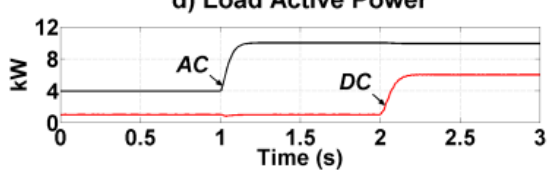

Fig. 9. Simulation results for the AC bus in Case 4.

\section{Case 3}

The TC is assumed to be in conducting mode; hence the $\mathrm{AC}$ and $\mathrm{DC}$ bus are inter-connected while the $\mathrm{AC}$ bus is assumed to be islanded from the grid. Under such conditions, the DERs in each bus share the load of the relevant bus and the $\mathrm{TC}$ regulates the voltage in both $\mathrm{AC}$ and $\mathrm{DC}$ bus. In this case, the central controller operates as backup for TC.

First, Let us assume the network is initially in steady-state condition with a load demand of approximately $3 \mathrm{~kW}$ in the AC bus. At $t=1 \mathrm{~s}$, this load is increased by $2 \mathrm{~kW}$ (i.e. $66 \%$ ) while the load connected to the DC bus is not changed. The output active power ratio among DER-1 and 2, connected to the $\mathrm{AC}$ bus is maintained as 1:2 (Fig. 7a). Similar power sharing is observed for DER-3 and DER-4, connected to the DC bus (Fig. 7b). The AC bus load variation (Fig. 7c) is only contributed by the DERs in the AC bus. The frequency and voltage variations in $\mathrm{AC}$ bus are within acceptable limits (Fig $7 \mathrm{~d}-\mathrm{e}$ ) and DC bus voltage is remained unaffected (Fig. 7f).

Now, let us consider the previous network with a load demand of approximately $3 \mathrm{~kW}$ in the DC bus. At $t=1 \mathrm{~s}$, this load is increased by $3 \mathrm{~kW}$ (i.e. $100 \%$ ). As the load change is in the DC bus, the output power of DERs in the AC bus is not affected (Fig. 8a); hence, the AC bus voltage and frequency will not be affected, too. However, this load change is shared by the DERs in the DC bus while the output active power ratio among them is maintained as 1:2 (Fig. 8b).

\section{Case 4}

The TC is assumed to be in conducting mode; hence, the $\mathrm{AC}$ and DC bus are interconnected while the AC bus is assumed to be connected to the grid. Under such conditions, the DERs in the AC bus operate in constant PQ mode and the DERs in the DC bus operate in constant P mode. The extra power required by the loads or the surplus of the generated power by the DERs is exchanged by the grid.

Let us consider the network is initially in steady-state condition with a load demand of $4 \mathrm{~kW}$ in the AC bus and $1 \mathrm{~kW}$ in the DC bus. At $t=1 \mathrm{~s}$, a load increase of $6 \mathrm{~kW}$ (i.e. 150\%) is applied in the $\mathrm{AC}$ bus and at $t=2 \mathrm{~s}$, a load increase of 5 $\mathrm{kW}$ (i.e. $500 \%$ ) is applied in the DC bus. The load changes are very high to result in power flow reversing over the TC. Through the simulations (Fig. 9a-d), it is shown that at $t<1$ $\mathrm{s}$, the $4 \mathrm{~kW}$ surplus of the power generated by DC DERs, is flowing from DC bus to AC bus and the total $6 \mathrm{~kW}$ surplus in $\mathrm{AC}$ bus is flowing to grid (Fig. 9c). As the load in the AC bus is increased at $t=1 \mathrm{~s}$, the power flow over the TC is maintained to $4 \mathrm{~kW}$ as before. In this case, since the power generation and demand in the $\mathrm{AC}$ bus are equal, therefore, the power exchange between the NG and grid is zero. At $t=2 \mathrm{~s}$, as the load in DC bus increases, the power flow over the TC is reversed and this time approximately $2 \mathrm{~kW}$ is transferred from the AC bus to DC bus. Hence, bidirectional power flow between the bus as well as the NG and grid are validated. 


\section{CONCLUSION}

The operation and control of Nanogrid, as the power supply unit for future community houses, is presented in this paper. The structure accommodates the integration of different types of $\mathrm{AC}$ and DC micro sources to supply the $\mathrm{AC}$ and DC loads within the community houses. The DERs are controlled in constant power output mode in grid-connected periods while they are controlled in droop-based voltage control during off-grid periods. The tie-converter, between the $\mathrm{AC}$ and DC bus, is controlled to regulate the voltage in each bus as well as providing a desired level of power flow between the two buses, in different modes of operation.

\section{APPENDIX}

Table I. Technical data of the network and DERs in simulation cases.

\begin{tabular}{|c|c|c|c|c|c|}
\hline $\begin{array}{l}\text { Medium Vol } \\
11 \mathrm{kV} \mathrm{L}-\mathrm{L}, 5 \\
\text { Transformer } \\
30 \mathrm{kVA}, 11 \mathrm{k} \\
\text { AC Bus } \\
410 \mathrm{~V} \mathrm{~L}-\mathrm{L} \mathrm{R} \\
\text { DC Bus } \\
350 \mathrm{~V} \\
\text { DER and TC } \\
R_{f}=0.1 \Omega, L_{f}\end{array}$ & $\begin{array}{l}(\mathrm{MV}) \mathrm{Fe} \\
R=0.2 \\
10 \mathrm{~V}, 5 \mathrm{C} \\
50 \mathrm{~Hz} \\
\mathrm{Cs} \text { and } \mathrm{F} \\
66 \mathrm{mH}, \mathrm{C}\end{array}$ & $\begin{array}{l}=10 \mathrm{~m} \\
\mathrm{~V} / \mathrm{Y}-\mathrm{G}\end{array}$ & nded, $Z_{I}=5$ & & \\
\hline & DER & droop & trol parame & & \\
\hline$\overline{\text { DER }}$ & $\begin{array}{c}\text { Rating } \\
{[\mathrm{kW}]}\end{array}$ & $\begin{array}{c}L_{T} \\
{[\mathrm{mH}]}\end{array}$ & $\begin{array}{c}m \\
{[\mathrm{rad} / \mathrm{kW}]}\end{array}$ & $\begin{array}{c}n \\
{[\mathrm{~V} / \mathrm{kVAr}]}\end{array}$ & $\begin{array}{c}m^{\prime} \\
{[\mathrm{V} / \mathrm{kW}]}\end{array}$ \\
\hline DER-1(AC) & 2.0 & 2.72 & 3.1416 & 18 & - \\
\hline DER-2(AC) & 4.0 & 1.36 & 1.5708 & 9 & - \\
\hline DER-3(DC) & 1.0 & - & - & - & 35 \\
\hline DER-4(DC) & 2.0 & - & - & - & 17.5 \\
\hline
\end{tabular}

\section{REFERENCES}

[1] J. Bryan, R. Duke and S. Round, "Decentralized generator scheduling in a nanogrid using DC bus signaling," IEEE Power Engineering Society General Meeting, pp. 977-982, Vol. 1, June 2004.

[2] A. Sannino, G. Postiglione and M.H.J. Bollen, "Feasibility of a DC network for commercial facilities," IEEE Trans. on Industry Applications, Vol. 39, No. 5, pp. 1499-1507, Sept./Oct. 2003.

[3] A. Goikoetxea, J.M. Canales, R. Sanchez and P. Zumeta, "DC versus AC in residential buildings: Efficiency comparison," IEEE EUROCON Conference, pp. 1-5, July 2013.

[4] Y. Hayashi, "High power density rectifier for highly efficient future DC distribution system," Electrical Engineering Research, Vol. 1, Issue 3, pp. 49-59, July 2013.

[5] H. Kakigano, Y. Miura and T. Ise, "Low-voltage bipolar-type DC microgrid for super high quality distribution," IEEE Trans. on Power Electronics, Vol. 25, No. 12, pp. 3066-3075, Dec. 2010.

[6] H. Kakigano, Y. Miura and T. Ise, "Distribution voltage control for DC microgrids using fuzzy control and gain-scheduling technique," IEEE Trans. on Power Electronics, Vol. 28, No. 5, pp. 2246-2258, May 2013.

[7] I. Cvetkovic, D. Dong, Z. Wei, et al. "A testbed for experimental validation of a low-voltage DC nanogrid for buildings," IEEE $15^{\text {th }}$ Int. Power Electronics and Motion Control Conf. (EPE/PEMC), Sept. 2012.

[8] A. Suzdalenko, M. Vorobyov and I. Galkin, "Development of distributed energy management system for intelligent household electricity distribution grid," IEEE EUROCON Conf., pp. 1474-1478, July 2013.

[9] F. Shahnia, R.P.S. Chandrasena, S. Rajakaruna and A. Ghosh, "Primary control level of parallel DER converters in system of multiple interconnected autonomous microgrids within self-healing networks," IET Generation, Transmission.\& Distribution, Vol. 8, no. 2, pp. 203-222, Feb. 2014

[10]A. Tewari, Modern Control Design with Matlab and Simulink, Wiley, 2002.

[11]X. Lu, J.M. Guerrero, S. Kai and J.C. Vasquez, "An improved droop control method for de microgrids based on low bandwidth communication with dc bus voltage restoration and enhanced current sharing accuracy," IEEE Trans. on Power Electronics, Vol. 29, No. 4, pp. 18001812, April 2014.

[12] M. Akbari, M, S.M.M. Tafreshi and M.A. Golkar, "Voltage control of a hybrid ac/dc microgrid in stand-alone operation mode," IEEE Innovative Smart Grid Technologies Conf. (ISGT India), pp. 363-367, Dec. 2011. 